University of Nebraska - Lincoln

DigitalCommons@University of Nebraska - Lincoln

\title{
Anisotropic Sm-(Co,Fe) Nanoparticles by Surfactant-assisted Ball Milling
}

Nilly Akdogan

University of Delaware, Newark, Delaware 19716, USA

George C. Hadjipanayis

University of Delaware, hadji@udel.edu

David J. Sellmyer

University of Nebraska-Lincoln, dsellmyer@unl.edu

Follow this and additional works at: https://digitalcommons.unl.edu/physicssellmyer

Part of the Physics Commons

Akdogan, Nilly; Hadjipanayis, George C.; and Sellmyer, David J., "Anisotropic Sm-(Co,Fe) Nanoparticles by Surfactant-assisted Ball Milling" (2009). David Sellmyer Publications. 216.

https://digitalcommons.unl.edu/physicssellmyer/216

This Article is brought to you for free and open access by the Research Papers in Physics and Astronomy at DigitalCommons@University of Nebraska - Lincoln. It has been accepted for inclusion in David Sellmyer Publications by an authorized administrator of DigitalCommons@University of Nebraska - Lincoln. 


\title{
Anisotropic Sm-(Co,Fe) nanoparticles by surfactant-assisted ball milling
}

\author{
Nilay G. Akdogan, ${ }^{1, a)}$ George C. Hadjipanayis, ${ }^{1, b)}$ and David J. Sellmyer ${ }^{2}$ \\ ${ }^{1}$ Department of Physics and Astronomy, University of Delaware, Newark, Delaware 19716, USA \\ ${ }^{2}$ Department of Physics and Astronomy, University of Nebraska, Lincoln, Nebraska 68588, USA
}

(Presented 14 November 2008; received 17 September 2008; accepted 3 November 2008; published online 12 February 2009)

\begin{abstract}
Magnetically hard $\mathrm{Sm}_{2}\left(\mathrm{Co}_{0.8} \mathrm{Fe}_{0.2}\right)_{17}$ and $\mathrm{SmCo}_{5}$ nanoparticles have been produced by using surfactant-assisted low- and high-energy ball milling techniques. Surfactants prevent the rewelding of the crashed particles during the milling process. Heptane was used as the milling medium and oleic acid as the surfactant. High-energy ball milling experiments took place in a milling vial with carbon steel balls by using an SPEX 8000M high-energy ball milling machine. The coercivity was found to increase with milling time with values of $2.3 \mathrm{kOe}$ for $\mathrm{Sm}_{2}\left(\mathrm{Co}_{0.8} \mathrm{Fe}_{0.2}\right)_{17}$ and $18.6 \mathrm{kOe}$ for $\mathrm{SmCo}_{5}$ after $4 \mathrm{~h}$ of milling. Transmission electron microscopy data showed that the milled powders consisted of nanoparticles with an average size of 5-6 $\mathrm{nm}$ and a narrow size distribution. Samples deposited on copper coated carbon grid showed self-assembled nanoparticles which could be further aligned when subjected to a magnetic field. (C) 2009 American Institute of Physics.
\end{abstract}

[DOI: $10.1063 / 1.3067851]$

\section{INTRODUCTION}

Recently, magnetically hard nanoparticles produced by ball milling have attracted great interest because of their applications. ${ }^{1}$ Very few studies exist on the preparation of magnetically hard nanoparticles of intermetallic compounds including those via sputtering ${ }^{2}$ and ball milling. ${ }^{3}$ Among all the known materials, Sm-Co based alloys have the highest magnetocrystalline anisotropy and therefore are very desirable for potential applications. Recently, significant efforts have been made in producing $\mathrm{Sm}-\mathrm{Co}$ nanoparticles. Recent studies reported a considerable progress in the synthesis of Sm-Co (Ref. 4) and $\mathrm{Nd}-\mathrm{Fe}-\mathrm{B}^{4,5}$ nanoparticles via surfactant-assisted ball milling as well as in the particle size selection of milled nanoparticles. ${ }^{6}$ However, the roomtemperature coercivity of the as-synthesized nanoparticles with a size below $30 \mathrm{~nm}$ did not exceed $3 \mathrm{kOe}$.

Due to the nature of high-energy ball milling (HEBM), cold welding processes usually take place, which lead to an increase in the average particle size. Therefore, the best approach for the preparation of magnetic nanoparticles is to use an appropriate surfactant and organic carrier liquid which enable us to obtain nanoscale particles. ${ }^{4}$

In this study, we have investigated the change in size and magnetic properties of magnetically hard $\mathrm{Sm}_{2}\left(\mathrm{Co}_{0.8} \mathrm{Fe}_{0.2}\right)_{17}$ and $\mathrm{SmCo}_{5}$ alloys by using a surfactant-assisted HEBM technique. $\mathrm{Sm}_{2}\left(\mathrm{Co}_{0.8} \mathrm{Fe}_{0.2}\right)_{17}$ nanoparticles have been obtained with narrow size distribution and significant roomtemperature coercivities.

\section{EXPERIMENTS}

$\mathrm{Sm}_{2}\left(\mathrm{Co}_{0.8} \mathrm{Fe}_{0.2}\right)_{17}$ and $\mathrm{SmCo}_{5}$ alloys were prepared by arc melting using pure metals. The ingots were homogenized

\footnotetext{
a) Electronic mail: nakdogan@udel.edu.

b) Author to whom correspondence should be addressed. FAX: 1-302-8311637. Tel.: 1-302-831-6289. Electronic mail: hadji@udel.edu.
}

for $12 \mathrm{~h}$ at $1000{ }^{\circ} \mathrm{C}$. Pulverizing techniques included crushing the homogenized alloys, grinding down to $200 \mu \mathrm{m}$, and HEBM with an SPEX-8000 mill. We used heptane (99.8\%) as the milling medium and oleic acid $(90 \%)$ as the surfactant. HEBM experiments took place in a milling vial with carbon steel balls by using an SPEX 8000M milling machine. The sample was milled for $0.5,1,2,4,6,8$, and $12 \mathrm{~h}$ with balls which were different in diameter. A ball-to-powder weight ratio of 10:1 was used. The amount of surfactant used was $10 \%$ by the weight of the starting powder.

Structure and morphology of the samples were examined by using Philips $3100 \mathrm{x}$-ray diffractometer (XRD). Transmission electron microscopy (TEM) was performed with a JEOL JEM-3010 instrument. Samples for TEM were prepared by letting the diluted slurry to dry on carbon coated copper grids. Magnetic properties were measured with a vibrating sample magnetometer on field-aligned powder samples embedded into wax.

\section{RESULTS AND DISCUSSION}

Figure 1 shows the $\mathrm{x}$-ray data for different milling times. The ingot has the ordered 2:17 rhombohedral structure. $\mathrm{X}$-ray data did not reveal the presence of oxides, iron, or cobalt at any stage of the milling process. As the alloy is milled, the XRD peaks are getting broader, indicating a smaller crystallite size. The starting particle size is around $200 \mu \mathrm{m}$. After $4 \mathrm{~h}$ milling the average crystallite size found via Scherrer's formula is around $8 \mathrm{~nm}$.

Figure 2 presents the TEM image and the corresponding selected area electron diffraction (SAED) for the powder milled for $4 \mathrm{~h}$. The figure features separate particles having an average size of 5-6 nm and a narrow size distribution. Indexed SAED image also proved 2:17 structure. It can be seen from Fig. 2 that samples deposited on carbon coated grid showed self-assembled nanoparticles. We have observed that when the specimen was field aligned, the (006) peak was 


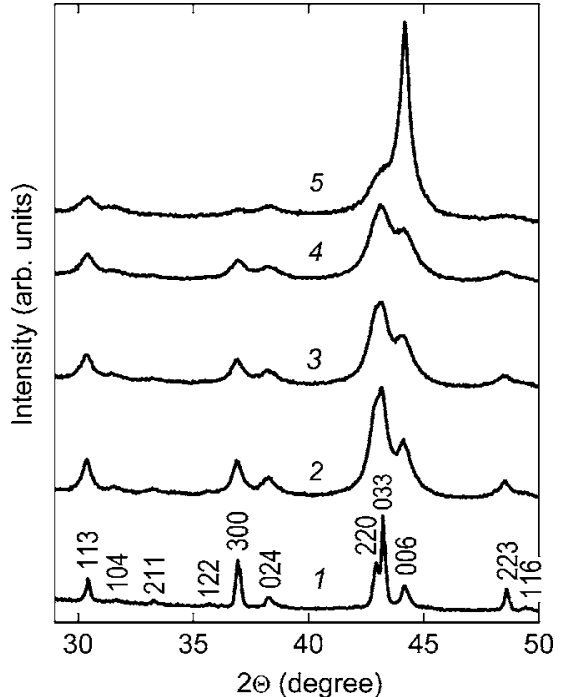

FIG. 1. X-ray diffraction data for a $\mathrm{Sm}_{2}(\mathrm{Co}, \mathrm{Fe})_{17}$ alloy which was homogenized (1) and milled for $1 \mathrm{~h}(2), 2 \mathrm{~h} \mathrm{(3),} \mathrm{and} 4 \mathrm{~h} \mathrm{(4)} \mathrm{and} \mathrm{field} \mathrm{aligned} \mathrm{after}$ the $4 \mathrm{~h}$ milling (5). The rhombohedral 2:17 structure is indexed.

enhanced which indicated that most of the particles were single crystalline and aligned in the easy direction (Fig. 1). As seen in Fig. 3, high resolution TEM images revealed anisotropic single crystalline nanoparticles. The $d$-spacings were measured in the lattice-imaging micrographs and found to match the rhombohedral $(\mathrm{hkl})$ peaks. The energy disper-

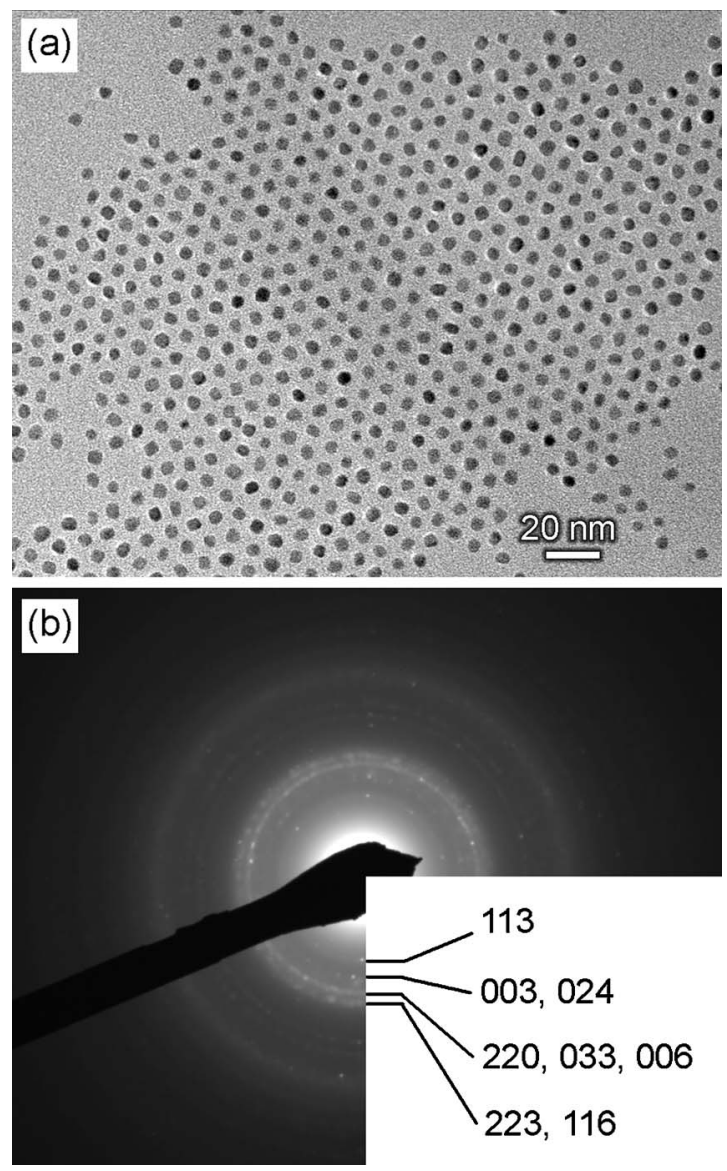

FIG. 2. TEM bright field image of the $4 \mathrm{~h}$ milled 2:17 alloy and corresponding indexed SAED image.

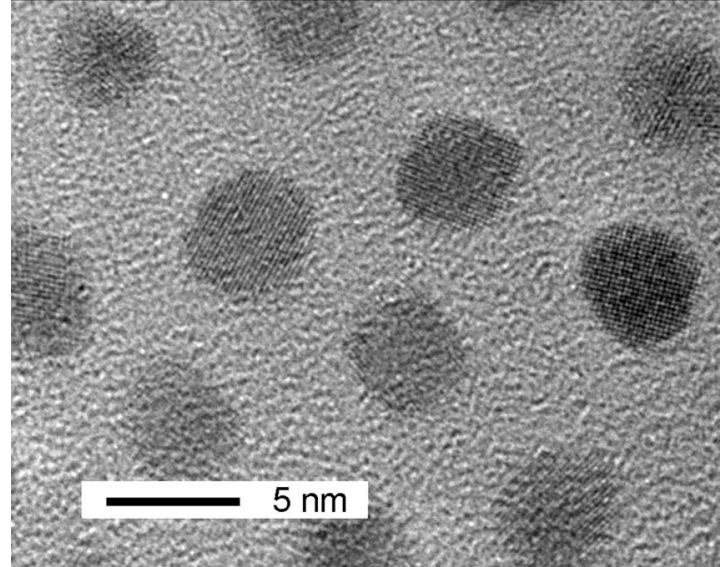

FIG. 3. High resolution TEM image of the $4 \mathrm{~h}$ milled 2:17 alloy.

sive spectroscopy revealed that the composition of the nanoparticles was the same as in the starting $\mathrm{Sm}_{2}\left(\mathrm{Co}_{0.8} \mathrm{Fe}_{0.2}\right)_{17}$ alloy.

During the HEBM, the sample was milled for $0.5,1,2$, $4,6,8$ and $12 \mathrm{~h}$ and the corresponding coercivities were 1.2, 1.4, 1.9, 2.3, 2.6, 2.8, and $2.88 \mathrm{kOe}$, respectively (Fig. 4). After $8 \mathrm{~h}$ of milling, the coercivity was saturated at around $2.8 \mathrm{kOe}$. Figure 4 shows coercivity and size change as the sample was ball milled. Compared to previous work, ${ }^{6}$ the coercivity of $4 \mathrm{~h}$ milled sample with an average size of 5-6 $\mathrm{nm}$ was significantly higher. The remanence values decreased with increasing milling time due to the loss of magnetocrystalline anisotropy; however, it should be noted that the sample was not washed and this may affect the actual values of magnetization.

For comparison, $\mathrm{SmCo}_{5}$ alloy was ball milled under the same conditions. Coercivity versus milling time (Fig. 4) showed much higher values compared to the 2:17 alloy, also compared to regular HEBM. When the sample was milled for $30 \mathrm{~min}$, its coercivity rapidly increased to $15 \mathrm{kOe}$ and continued to increase with increasing milling time. This work clearly demonstrated that the magnetic properties of surfactant-assisted ball milled $\mathrm{SmCo}_{5}$ alloy were significantly better compare to regular ball milling. ${ }^{3}$ Magnetic properties were even better than the other reported works. ${ }^{3,4}$ When the same powder was aligned perpendicular to the

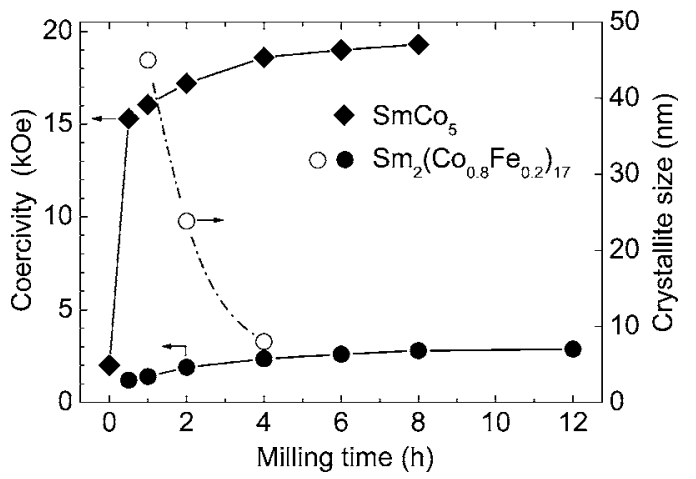

FIG. 4. Coercivity vs milling time graph for 1:5 and 2:17 alloys (maximum applied field was $20 \mathrm{kOe}$ ). 


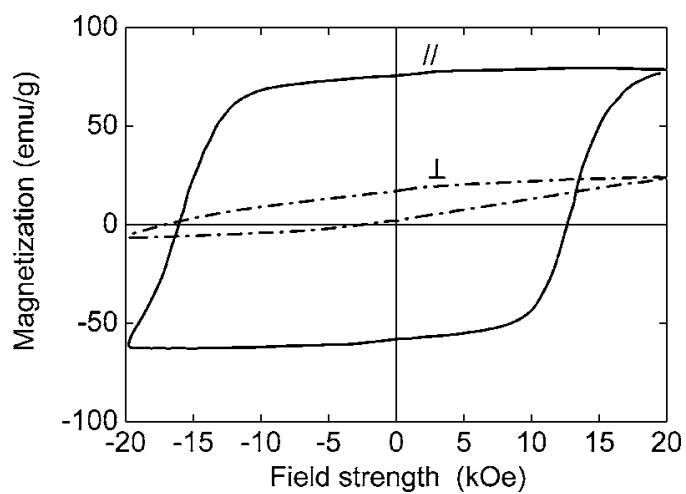

FIG. 5. Hysteresis loops for the 1:5 nanoparticles (maximum applied field was $20 \mathrm{kOe})$.

applied field (Fig. 5), one can see that the particles are anisotropic. Further morphology and structure analysis is underway for $\mathrm{SmCo}_{5}$.

\section{CONCLUSION}

In this work, we have fabricated Sm-Co nanoparticles with enhanced magnetic properties using surfactant-assisted ball milling. The magnetic, structural, and morphological properties of 2:17 and 1:5 have been studied. Unlike the regular HEBM which decreases the coercivity after some time, surfactant-assisted HEBM gives rise to significantly high room-temperature coercivities with milling for both alloys.

\section{ACKNOWLEDGMENT}

The authors would like to thank A. M. Gabay for helpful discussions. This work was supported by DOE.

${ }^{1}$ S. Sun, C. B. Murray, D. Weller, L. Folks, and A. Moser, Science 287, 1989 (2000).

${ }^{2}$ S. Stoyanov, V. Skumryev, Y. Zhang, Y. Huang, G. Hadjipanayis, and J. Nogues, J. Appl. Phys. 93, 7592 (2003).

${ }^{3}$ E. M. Kirkpatrick, S. A. Majetich, and M. E. McHenry, IEEE Trans. Magn. 32, 4502 (1996).

${ }^{4}$ V. M. Chakka, B. Altuncevahir, Z. Q. Jin, Y. Li, and J. P. Liu, J. Appl. Phys. 99, 08E912 (2006).

${ }^{5}$ H. G. Cha, Y. H. Kim, C. W. Kim, H. W. Kwon, and Y. S. Kang, J. Phys. Chem. 111, 1219 (2006).

${ }^{6}$ Y. Wang, Y. Li, C. Rong, and J. Ping Liu, Nanotechnology 18, 465701 (2007). 